\title{
The Effects of No Child Left Behind on the Prevalence of Evidence-Based Drug Prevention Curricula in the Nation's Middle Schools*
}

\section{Chris Ringwalt, DrPH ${ }^{\mathrm{a}}$, Sean Hanley, $\mathrm{MPH}^{\mathrm{b}}$, Susan T. Ennett, PhD, MSPH ${ }^{\mathrm{c}}$, Amy A. Vincus, MPH $^{d}$, J. Michael Bowling, PhD $^{e}$, Susan W. Haws, MPH ${ }^{f}$, and Louise A. Rohrbach, PhD, MPHg}

Chris Ringwalt: ringwalt@pire.org; Sean Hanley: shanley@pire.org; Susan T. Ennett: sennett@email.unc.edu; Amy A. Vincus: avincus@pire.org; J. Michael Bowling: jbowling@email.unc.edu; Susan W. Haws: haws@email.unc.edu; Louise A. Rohrbach: rohrbac@usc.edu

aSenior Research Scientist, Pacific Institute for Research and Evaluation, 1516 East Franklin Street, Suite 200 Chapel Hill, NC 27514

${ }^{\mathrm{b}}$ Research Associate, Pacific Institute for Research and Evaluation, 1516 East Franklin Street, Suite 200, Chapel Hill, NC 27514

${ }^{\mathrm{c}}$ Associate Professor, Department of Health Behavior and Health Education, University of North Carolina at Chapel Hill, 358A Rosenau Hall, Chapel Hill, NC 27599

${ }^{\mathrm{d}}$ Associate Research Scientist, Pacific Institute for Research and Evaluation, 1516 East Franklin Street, Suite 200, NC 27514

${ }^{e}$ Research Associate Professor, Department of Health Behavior and Health Education, University of North Carolinaat Chapel Hill, 312 Rosenau Hall, Chapel Hill, NC 27599

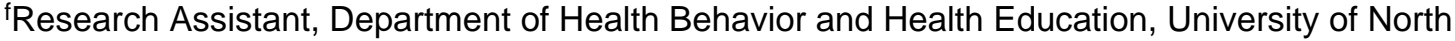
Carolina at Chapel Hill, 358A Rosenau Hall, NC 27599

${ }^{9}$ Associate Professor of Research, Department of Preventive Medicine, Institute for Prevention Research, University of Southern California, 1000 S. Fremont Ave., Unit \#8, Alhambra, CA 91803

\section{Abstract}

BACKGROUND-Concerns have been expressed that No Child Left Behind (NCLB) may be reducing the amount of classroom time devoted to subjects other than those for which students are tested. The purpose of this article is to explore whether NCLB legislation has affected the provision of evidence-based drug prevention curricula (EBC) in the nation's middle schools, a subject area that is not assessed by standardized tests.

\footnotetext{
*Indicates CHES and Nursing continuing education hours are available. Also available at: http://www.ashaweb.org/ continuing_education.html

(C) 2011, American School Health Association

Address correspondence to: Chris Ringwalt, Senior Research Scientist, (ringwalt@pire.org), Pacific Institute for Research and Evaluation, Chapel Hill, NC 27514.

Human Subjects Approval Statement

This study was considered exempt from human subjects review by the Pacific Institute for Research and Evaluation's Institutional Review Board (FWA0000 3078).
} 
METHODS—Data were collected in spring 2005 and spring 2008 from a nationally representative sample of middle schools. Respondents completed a survey regarding their provision of EBC (2005 response rate: 78.1\%). We also collected data on schools' adequate yearly progress (AYP) status as of 2005 as a measure of their compliance with NCLB targets. We restricted our sample to schools that responded to our survey in both waves ( $\mathrm{n}=1324$, or $76.9 \%$ of those schools responding in 2005) and conducted logistic regression analyses to determine whether those schools not making AYP in 2005 were less likely to be using an EBC in 2008.

RESULTS-Our results revealed no relationship between AYP status in 2005 and EBC use in 2008. Analyses of demographic characteristics showed that schools making AYP were more likely to be small and rural, and to serve majority White student populations whose families were characterized by lower levels of poverty.

CONCLUSIONS-Our failure to find any relationship between AYP status and the provision of EBC suggests that concerns about the potential adverse effects of NCLB on drug use prevention have yet to be validated. Implications of our results are discussed.

\section{Keywords}

policy; curriculum; drugs

Concerns have been expressed that the No Child Left Behind (NCLB) Act may be reducing the amount of classroom time devoted to subjects other than those for which schools are held responsible, namely math, science, and reading. ${ }^{1}$ To the extent that the concern is accurate, schools—and especially those that are not performing well—may be "narrowing the curriculum" by allocating resources and time away from school health, physical education, and other extracurricular activities. ${ }^{2-11}$ However, available trend data that speak to potential adverse effects of NCLB on schools' provision of health education content are scant, ambiguous, and contradictory. The purpose of this paper is to explore whether NCLB legislation has affected the provision of evidence-based drug prevention curricula in the nation's middle schools, a subject area that is not assessed by standardized tests. These curricula typically require between 8 and 15 class periods to administer, and thus may impose considerable demands on schools' limited classroom time. The link between drug use and academic performance, however, is well established and a number of studies have shown that drug use may serve as a risk factor for poor academic performance. ${ }^{12-14}$ Neglecting evidence-based strategies for drug use prevention, therefore, would be counter productive to schools' efforts to improve academic achievement.

Originally passed in 2001 as a reauthorization of the Elementary and Secondary Education Act, the primary objective of NCLB ${ }^{15}$ is to enhance students' learning and academic achievement. The law gives particular emphasis to reducing disparities in students' performance among key subgroups, as defined by poverty, racial or ethnic minority status, English language proficiency, and special needs. The intent of the law is to ensure that all students score at a basic level of proficiency by 2014, and test standards are required to rise each year to ensure that this goal is met. ${ }^{16}$ Accountability systems have been established in all of the states, each of which has developed its own set of procedures to determine whether its schools are making adequate yearly progress (AYP) by means of their students' scores on 
standardized tests. All states now make available lists of schools that are not making satisfactory progress, and parents are given the option of transferring their children elsewhere. Those schools not making AYP for 2 consecutive years face increasing levels of sanctions in subsequent years, ranging from the development of a school improvement plan to the initiation of school restructuring. As of the 2005-2006 school year, 17\% of all public schools were not making AYP; ${ }^{17}$ by 1 year later, that proportion had increased to almost $20 \% .{ }^{16}$ Given the threat of school restructuring that is built into NCLB, it is reasonable to assume that administrators and teachers in schools that are failing to make AYP are concerned about their tenure, and that they may as a result be narrowing the curriculum to concentrate their schools' resources on "teaching to the test." 18

Empirical evidence that NCLB has actually attenuated school time devoted to subjects other than math, science, and reading is scant. A study of NCLB's effects in Chicago Public Schools, published in 2003, found that the resources devoted to non-tested material seemed to be decreasing over time. ${ }^{19}$ Data from the Schools and Staffing Survey of the US Department of Education indicated a modest reduction between 1987 and 2003 in the amount of time that elementary school teachers were spending on social studies, and a concomitant increase in time devoted to math and English. The same study yielded no evidence, however, of curriculum narrowing in middle schools. ${ }^{20}$ More recently, results from a survey conducted in 2007 of 349 nationally representative school districts suggested that $49 \%$ had reduced the amount of time allocated in their elementary schools for physical education, art and music, science and social studies, and recess. At the same time, $62 \%$ were spending more time on English or mathematics. ${ }^{21}$ On the other hand, an analysis of annual iterations of the Monitoring the Future survey does not reveal any marked decline in instructional time following the passage of NCLB in 2001 for subject areas not tested, even in middle schools where testing is most pronounced. ${ }^{20}$

In regards to instructional time related to the field of health education, data from the Centers for Disease Control and Prevention-sponsored School Health Policies and Procedures Survey suggest that the median number of hours that middle school teachers devoted to drug use prevention increased from 4.0 in 2000 to 5.5 in 2006, and hours allocated to sexually transmitted disease prevention increased from 1.3 to 1.8. On the other hand, the hours devoted to injury prevention and safety decreased from 3.6 to 1.8 during the same time period, whereas time spent on violence prevention decreased from 4.0 to 2.5 hours. Similar trends were observed in high schools, where the amount of time spent on teaching drug use and pregnancy prevention increased, whereas time allocated to injury prevention, safety, and violence prevention decreased. ${ }^{22,23}$

Among the many provisions of NCLB is a requirement that schools that receive money from the Office of Safe and Drug-Free Schools of the US Department of Education administer evidence-based strategies that address drug and violence prevention, ${ }^{15}$ or face losing their funding. ${ }^{24}$ Given that nearly all districts in the United States receive Safe and Drug-Free Schools funding, ${ }^{25,26}$ this is likely to be a salient concern for most districts and their associated schools. In 1999, 2005, and 2008, this article's authors conducted a survey of a nationally representative sample of schools with middle school grades, the primary purpose of which was to determine the proportion that were using evidence-based curricula (EBC) as 
specified in any of several national registries of such curricula. Although we did not observe a significant increase in use of EBC from 2005 to $2008,{ }^{27}$ data from our 2005 study indicated that $42.6 \%$ of the nation's middle schools were using at least one EBC, and $22.7 \%$ of respondents were using an EBC most frequently, while the remaining schools relied on curricula or other content related to drug prevention that lacked evidence of effectiveness. ${ }^{28}$ These figures represent a signficant increase as compared with baseline data that we collected in 1999 concerning schools' use of at least one EBC, ${ }^{28}$ which indicate that they began implementing EBC in larger numbers leading up to and immediately following the passing of the NCLB legislation in 2001. This trend may be attributable to the provisions of the Principles of Effectiveness that were promulgated in 1998 and later enshrined in NCLB legislation, and that require the use of EBC in schools receiving support from the Office of Safe and Drug-Free Schools.

Capitalizing on the longitudinal nature of our repeated surveys of drug prevention practices in the nation's middle schools, we examined the relationship between schools' AYP status and their subsequent use of evidence-based drug use prevention curricula. Specifically, we were interested in learning whether schools that were failing to make AYP in 2005 would be less likely than those making AYP to use EBC 3 years later, because school administrators were devoting their resources and classroom time to bring their schools into compliance with the demands of NCLB. Therefore we hypothesized that relative to schools that were making AYP in 2005, those that were not making AYP that year would be less likely to:

1. continue using EBC in 2008 if they were using EBC in 2005, and

2. adopt $\mathrm{EBC}$ by 2008 if they were not using $\mathrm{EBC}$ in 2005 .

\section{METHODS}

We utilized data from our longitudinal study of a large nationally representative sample of the nation's middle schools conducted in 2005 and repeated in 2008, the primary purpose of which was to assess the prevalence of evidence-based drug prevention curricula. Within the 2005 sample, we identified whether each school was (1) using such curricula and (2) making AYP. We then determined which schools were using EBC 3 years later. Analyses pertinent to the first hypothesis utilized data from schools using EBC in 2005; those concerning the second hypothesis pertained to schools not using EBC that year.

\section{Subjects}

Data come from the School-Based Substance Use Prevention Programs Study, a nationwide survey of drug prevention activities in the nation's middle schools conducted in 1999, 2005, and 2008. The sample for the original survey, conducted in 1999, utilized a 1997-1998 sampling frame from Quality Education Data, Inc., ${ }^{29}$ which comprised all regular schools in the 50 states and the District of Columbia with middle school grades. We defined eligible schools as those that included grades 7 or 8 , or were limited either to the sixth grade or to the fifth and sixth grades. We excluded schools with fewer than 20 students and those that focused exclusively on special education or vocational development. The sampling frame yielded 2273 eligible public schools. ${ }^{30}$ For the 2005 survey, we supplemented the 1999 sample with 210 additional schools selected from a 2002 to 2003 sampling frame supplied 
by the Common Core of Data ${ }^{31}$ to account for schools that opened between 1999 and 2003.

Given the high variability of the characteristics of middle schools across the country, we stratified our samples with equal probability within each stratum, to ensure adequate representation of schools along 3 key charactistics: population density, school size, and poverty level. The purpose of stratifying was to reduce sampling error and thus increase the precision of our estimates.

Between October 2004 and January 2005, before the 2005 survey data collection, we contacted all schools $(n=2483)$ to confirm their status, a process that yielded 2204 schools that met our eligibility criteria. The residual $(n=279)$ was considered ineligible either because of their grade span, school type, and school size, or because the school had closed in the interim. We also excluded those schools that indicated that they had no staff whatsoever who taught drug prevention content. We conducted a similar screening procedure before the 2008 survey data collection to verify schools' eligibility status. Our analyses are restricted to those schools that responded to the survey in both 2005 and $2008(\mathrm{n}=1324)$.

\section{Instruments}

In the 2005 and 2008 survey administrations, we asked respondents to indicate which of 26 drug prevention curricula, if any, they taught in their school's middle school grades during the current school year. We then asked them which of the curricula they used most frequently. Respondents also identified in an open-ended field the names of any curricula we did not specify. Respondents who completed the survey by telephone identified which curicula they used most frequently and their responses were then coded into our list of curricula. Copies of our instruments are available from the first author.

For the purposes of this paper, we consider EBC to be those curricula that were designed to prevent drug use, targeted a universal population of middle school students, were commercially available as of the 2004-2005 school year, and were identified as evidencebased as of 2004 on any of 3 national registries. Our list of EBC included those identified as: "model" or "effective" by the Substance Abuse and Mental Health Services Administration's National Registry of Evidence-Based Programs and Practices; ${ }^{32}$ as "model" or "promising" by "Blueprints for Violence Prevention," 33 or as "exemplary" by the Office of Safe and Drug-Free Schools. ${ }^{34}$ Collectively, these reviews identified the following 10 curricula as EBC: All Stars, keepin' it REAL, Life Skills Training, Lions Quest Skills for Adolescence, Positive Action, Project ALERT, Project Northland, Project TNT, Social Competence Promotion Program for Young Adolescents, and Too Good for Drugs. The remaining 16 curricula were not evidence-based.

Procedure

The survey data used in these analyses were collected from January to July of 2005 and again in 2008 from the person considered to be the most knowledgeable about drug use prevention in each eligible school— that is, the individual with the most knowledge and understanding of the school's drug prevention activities. This individual was identified during the screening procedures used to identify schools' eligibility status. We directed our invitation to participate in the study to this individual. In neither 2005 nor 2008 did we 
attempt to return to the respondent for the previous iteration, but instead sought to identify the most qualified person to complete our survey.

In 2005 we utilized 3 sequential survey data collection modes to maximize our response rate. All respondents were initially invited by letter to complete a 40-45 minute survey via a secure Web site, for which they were provided a prepaid \$10 cash incentive. Respondents who did not complete the Web survey after repeated contacts received a paper copy of the survey along with a postage-paid return envelope. Those who failed to complete the paper survey were contacted for a brief interview. Altogether, $65.2 \%$ of the sample responded by Web, $18.9 \%$ by paper, and $15.9 \%$ by phone, which yielded a total response rate of $78.1 \%$ (n $=1721$ ). We proceeded in a similar fashion for the third administration of the survey except that we dispensed with the paper version. Of the 1721 responding schools in 2005, 1324 (76.9\%) schools completed the survey in $2008,83.2 \%$ by Web and the remainder (16.8\%) by phone.

In addition, we collected data concerning each school's AYP status as of the 2004-2005 school year from Web sites maintained by its respective state or from an associated organization, such as a university. We then coded each school as making or not making AYP based on its state's designation. For 18 schools that were not included on their state's list, we contacted the associated school district to determine the school's status as of 20042005. In the case of 4 states for which data were unavailable online, we sent a list of the schools in our sample to a state-level contact, who then identified the AYP status for each school. For 2 states reporting that they did not assess AYP status for the 2004-2005 school year, we determined the status as of the previous year for the 15 schools they contributed to the sample. We were unable to code AYP status for a total of 14 of our schools, which we excluded from our analysis file. In 8 cases, the school did not have an AYP status because its enrollment was too low to be assessed, whereas in another 4 cases the school did not contain grades for which students were assessed. The remaining 2 schools did not have an AYP status because they had been restructured.

We also secured from the 2004 to 2005 school Common Core of Data (CCD) data file ${ }^{35}$ information concerning each school's size and racial/ethnic composition, as well as the population density of the area in which the school was located and the proportion of its students who were eligible for a free or reduced-priced lunch, which we used as a proxy for poverty level.

\section{Data Analysis}

All analyses were conducted in SAS 9.1 (SAS Institute, Inc, Cary, NC) using weighted data and procedures that accounted for the study's complex sampling design. Sample weights were constructed from original probabilities of selection computed on the 1999 sample, ${ }^{36}$ in conjunction with probabilities of selecting new schools from the 2002 sample.

To assess the comparability of our analysis sample (ie, those responding to our survey in both 2005 and 2008) with those schools that only responded in 2005, we conducted RaoScott chi-square tests to determine whether there were differences in 2005 AYP status, population density, student poverty status, school size, and the race/ethnicity of the majority 
of the student population as reported on the 2004-2005 CCD. We next screened our data with respect to our questions regarding curriculum use and eliminated 6 cases for inconsistent responses, yielding a final analysis sample of 1318 .

We followed these analyses by computing the number and percentage of schools that used an EBC in 2008 as a function of their AYP status in 2005, for each of our 2 hypotheses, the first of which pertains to the subset of schools using EBC in 2005, and the second to the subset of schools not using them that year. This allowed us to conduct a preliminary examination of the nature of the relationship between AYP and EBC status for each of our hypotheses.

We then employed Rao-Scott chi-square tests to identify demographic characteristics that distinguished those schools that made AYP in 2005 from those that did not. The purpose of these analyses was to describe contextual differences in these 2 groups of schools and to identify characteristics that had the potential to confound the relationship between schools' AYP status and their use of EBC.

For our final analyses, we created 2 strata based on use of an EBC in 2005, which allowed us to test our 2 hypotheses. We then ran a series of logistic regression models for each stratum using the SURVEYLOGISTIC procedure in SAS. We first regressed 2008 EBC status on 2005 AYP status, then regressed 2008 EBC status on each demographic characteristic that distinguished between those making and not making AYP in 2005 identified in the preceding analysis. We concluded with a full model that regressed 2008 EBC status on 2005 AYP status controlling for the demographic characteristics. For these analyses, we coded schools' EBC and AYP status in such a manner that those not using 1 of the 10 specified EBC most frequently, and those making AYP, were scored 0 on these 2 dummy variables; that is, they served as referents. Using this coding scheme, we expected to see odds ratios less than 1.0 if our hypotheses were supported.

\section{RESULTS}

Our comparison of the AYP status and demographic characteristics of the schools responding and not responding to our survey in 2008 revealed one difference in that responding schools were more likely to be large $\left(\chi^{2}[2 \mathrm{df}]=15.02, \mathrm{p}<.001\right)$. Table 1 presents the distribution of our sample along dimensions of EBC use and AYP status. As can be seen for both schools using and not using an EBC most frequently in 2005, similar proportions of schools used an EBC in 2008 regardless of their AYP status in 2005.

The results of our demographic comparisons between schools making and not making AYP in 2005 are presented in Table 2. Schools making AYP were more likely to be small $\left(\chi^{2}[2\right.$ $\mathrm{df}]=85.28, \mathrm{p}<.001)$ and rural $\left(\chi^{2}[2 \mathrm{df}]=60.18, \mathrm{p}<.001\right)$, and to serve majority White student populations $\left(\chi^{2}[4 \mathrm{df}]=87.64, \mathrm{p}<.001\right)$ whose families were characterized by lower levels of poverty $\left(\chi^{2}[2 \mathrm{df}]=60.46, \mathrm{p}<.001\right)$.

In regards to our 2 hypotheses, our logistic regression analyses (Table 3) revealed no significant relationships between AYP status in 2005 and the use of an EBC in 2008 in either stratum. Among those using an EBC in 2005, those not making AYP in 2005 were as 
likely to continue using an EBC in 2008 as those who made AYP in 2005 (adjusted odds ratio $(A O R)=0.88, p>.05)$. Likewise, among those not using an EBC in 2005, those not making AYP were as likely to initiate use of an EBC by 2008 as those who made AYP in $2005(\mathrm{AOR}=1.26, \mathrm{p}>.05)$.

\section{DISCUSSION}

In this study, we found no support for the concern that schools not making annual yearly progress in 2005, relative to those doing so, would be less likely to continue using, or to initiate the use of, evidence-based drug prevention curricula in 2008. Thus, neither of our hypotheses was supported. That said, we should point out that the same NCLB legislation that requires schools to reach annually escalating AYP targets also mandates that schools use evidence-based drug and violence prevention programs or risk losing their funding. ${ }^{24}$ It is thus possible that schools not making AYP were at least partially deterred from eliminating their use of EBC for fear of suffering further negative consequences. If so, school health education curricula that address topic areas other than drugs and violence may be more vulnerable.

Our study has yielded data that suggest major differences between schools that made and did not make AYP in 2005. The former was much more likely to be small, located in rural relative to urban areas, and to comprise students who were White and from more affluent families. These findings serve as yet another reminder of the profound sociodemographic and contextual differences between schools that are and are not making AYP, and of the enormity of the task required to assist failing schools. Students are expected to achieve ever escalating levels of proficiency if they are to reach full proficiency in 2014, and schools with heterogeneous student populations have even more AYP benchmarks to meet than those serving homogenous populations.

\section{Limitations}

The interpretation of study findings should be tempered by a few concerns. First, although the basis on which we judged drug prevention curricula as effective was sound in 2005, it was less so in 2008. In the interim, the National Registry of Effective Prevention Programs and Practices, which yielded the majority of curricula we specified as evidence-based, changed its rating system. Although in 2005 it recognized programs as "model" if they satisfied 6 methodological criteria and yielded positive outcomes, by 2008 it had changed to a report of ratings for each of the criteria, and thus the classification of "model" no longer existed as such. For the purposes of this paper, we simply considered all curricula that were rated as evidence-based in 2005 to continue to be so in 2008 .

Second, we learned during the course of data collection concerning schools' AYP status in 2005 that the states vary considerably in the proficiency targets they set for their schools each year; thus scores on standardized tests that are considered acceptable in 1 state may be indicative of school failure in another. We do not believe that this variation affects the validity of our main findings related to the effects of AYP on the implementation of EBC, because it was the failure to make AYP per se that appeared likely to induce schools to concentrate their resources on the subjects for which they would be held responsible, 
irrespective of the criteria used to judge AYP. However, these varying criteria across states are likely to have introduced some error in the ancillary findings we reported concerning school characteristics related to AYP status. On the other hand, those findings were so robust—all were significant at $\mathrm{p}<.0001$ - that any error introduced is likely to be minor.

Third, we recognize that schools' AYP status may fluctuate from year to year, and that some schools that did not make AYP in 2005 may well have been restored to good standing by 2008. However, we were precluded by available study resources from determing which of our participating schools were making AYP as of 2008. Furthermore, this information was not directly related to our hypotheses, which concerned whether schools' AYP status as of 2005 affected their use of EBC 3 years later. It seems reasonable to expect that administrators in schools that did not make AYP in 2005 would remain sensitive to the possibility that they might fail again, particularly given the annual rise in proficiency benchmarks required by NCLB, and would likely continue any curricular changes and other modifications to their teaching practices made in response to their failure to make AYP in 2005.

\section{Conclusion}

This study is the first to examine, within the context of a large longitudinal sample, the effects of AYP status on the provision of evidence-based drug prevention curricula. Our failure to find any relationship between AYP status and the provision of EBC suggests that concerns about the potential adverse effects of NCLB on youth drug use prevention have yet to be validated. This issue should be explored further within the context of other longitudinal studies of trends in the time allotted to health education content in the nation's schools, which take into account the schools' AYP status. Given the amply demonstrated relationship between substance use and academic performance, we are pleased to have found that the 2 key elements of NCLB legislation discussed here do not appear to be mitigating against one another.

\section{IMPLICATIONS FOR SCHOOL HEALTH}

Although pressure on schools to devote time and resources to achieve or maintain AYP is great, particularly in light of escalating benchmarks and sanctions, we believe that the provision of evidence-based strategies for the prevention of youth drug use is synergistic with this goal. Research on the connection between educational success and drug use has generated a large body of literature, with some debate as to whether drug use causes poorer educational outcomes or vice versa. Using data from Monitoring the Future, a nationwide study of drug use and other behaviors among middle and high school students, Bachman and colleagues $^{12}$ found that although the evidence suggests that educational failure leads to subsequent drug use, the converse may be true as well; that is, drug use may cause poor educational outcomes. Providing students with effective drug prevention programming may, therefore, support schools' efforts to achieve the academic goals required by NCLB. Although our study does not allow us to test this notion, we hope that our results are an indication that schools recognize the interrelationship between drug use and academic achievement and are not narrowing the curriculum accordingly. As schools struggle to 
allocate time and resources toward achieving academic goals, we hope that they continue to recognize the important role that drug prevention plays in their students' academic lives.

In particular, we encourage schools to adopt or continue to use EBC in their provision of drug prevention education. Such curricula have been subjected to rigorous evaluations and have been shown to prevent or reduce drug use among adolescents. Our previous work ${ }^{27}$ has shown that although most schools use some type of drug prevention curricula in middle school grades, for example, most do not use an EBC as their primary curriculum. Given the diminishing resources devoted to drug prevention that many schools face, we encourage them to devote the scarce resources they do have to strategies that have been shown to work. Doing so may not only help to ensure the health of their students, but also the academic achievement of the school.

\section{References}

1. Rose, LC.; Gallup, AM. The 39th Annual Phi Delta Kappa/Gallup Poll of the Public's Attitudes Toward the Public Schools. Princeton, NJ: Phi Delta Kappa International and The Gallup Poll; 2007.

2. Valli L, Buese D. The changing roles of teachers in an era of high-stakes accountability. Am Educ Res J. 2007; 44(3):519-558.

3. Abril CR, Gault BM. The state of music in the elementary school: the principal's perspective. J Res Music Educ. 2006; 54:6-20.

4. Center on Education Policy. From the capital to the classroom: Year 4 of the No Child Left Behind Act. Washington, DC: Center on Education Policy; 2006. Available at: http://www.cep-dc.org/ index.cfm?fuseaction=Feature.showFeature \&featureID=7 [Accessed September 28, 2009]

5. Herman, J. Accountability and assessment: is public interest in K-12 education being served?. In: Ryan, K.; Shepard, L., editors. The Future of Test-Based Educational Accountability. New York, NY: Routledge; 2008. p. 211-232.

6. Manzo K. Social studies losing out to reading, math. Educ Week. 2005; 24(27):1, 16-17, $24-25$.

7. Marx RW, Harris CJ. No Child Left Behind and science education: opportunities, challenges, and risks. Elementary Sch J. 2006; 106(5):467-477.

8. National Association for Sport and Physical Education \& American Heart Association. Shape of the Nation Report: Status of Physical Education in the USA. Reston, VA: National Association for Sport and Physical Education; 2006.

9. Ratner GM. Why the No Child Left Behind Act needs to be restructured to accomplish its goals and how to do it. Univer Dist Columbia Law Rev. 2007; 9 UDC/DCSL L. Rev. 1.

10. Rothstein R, Jacobsen R. A test of time: unchanged priorities for student outcomes. Sch Administrator. 2007; 64:36-40.

11. von Zastrow, C.; Janc, H. Academic Atrophy: The Condition of the Liberal Arts in America's Public Schools. Washington, DC: Council for Basic Education; 2004.

12. Bachman, JG.; O’Malley, PM.; Schulenberg, JE.; Johnston, LD.; Freedman-Doan, P.; Messersmith, EE. The Education-Drug Use Connection: How Successes and Failures in School Relate to Adolescent Smoking, Drinking, Drug Use, and Delinquency. New York, NY: Taylor \& Francis Group/Lawrence Erlbaum Associates; 2008.

13. King KM, Meehan BT, Trim RS, Chassin L. Substance use and academic outcomes: synthesizing findings and future directions. Addiction. 2006; 101(12):1688-1689. [PubMed: 17156166]

14. Newcomb MD, Bentler PM. Drug use, educational aspirations, and work force involvement: the transition from adolescence to young adulthood. Am J Community Psychol. 1986; 14(3):303-321. [PubMed: 3739981]

15. US Department of Education. [Accessed June 6, 2009] No Child Left Behind Act of 2001. 2001. http://www.ed.gov/policy/elsec/leg/esea02/pg52.html\#sec4115 
16. Hoff DJ. Schools struggling to meet key goal on accountability: number failing to make AYP rises 28 percent. Educ Week. 2009; 28(16):1, 14-15.

17. Olson L. As AYP bar rises, more schools fail: percent missing NCLB goals climbs amid greater testing. Educ Week. 2006; 26(4):1, 20.

18. Olsen B, Sexton D. Threat rigidity, school reform, and how teachers view their work inside current education policy contexts. Am Educ Res J. 2009; 46(1):9-44.

19. Jacob BA. Getting inside accountability: lessons from Chicago. Brookings-Wharton Pap Urban Aff. 2003; 2003(1):41-81.

20. Levine, P.; Marcelo, KB.; Lopez, MH. Getting Narrower at the Base: The American Curriculum after NCLB. Medford, MA: Center for Information \& Research on Civic Learning \& Engagement (CIRCLE); 2008.

21. McMurrer, J. Instructional Time in Elementary Schools: A Closer Look at Changes for Specific Subjects. Washington, DC: Center on Education Policy; 2008.

22. Kann L, Brener N, Allensworth D. Health education: results from the School Health Policies and Programs Study 2000. J Sch Health. 2001; 71(7):266-278. [PubMed: 11586870]

23. Kann L, Telljohann SK, Wooley SF. Health education: results from the School Health Policies and Programs Study 2006. J Sch Health. 2007; 77(8):408-434. [PubMed: 17908101]

24. Gandhi AG, Murphy-Graham E, Petrosino A, Chrismer SS, Weiss CH. The devil is in the details: examining the evidence for "proven" school-based drug abuse prevention programs. Eval Rev. 2007; 31(1):43-74. [PubMed: 17259575]

25. Cho H, Hallfors DD, Iritani BJ, Hartman S. The influence of "No Child Left Behind" legislation on drug prevention in U.S. schools. Eval Rev. 2009; 33(5):446-463. [PubMed: 19429841]

26. Hantman, I.; Crosse, C. Progress in Prevention: National Study of Local Education Activities Under the Safe and Drug-Free Schools and Communities Act. Washington, DC: US Department of Education, Office of the Under Secretary, Planning and Evaluation Service; 2000.

27. Ringwalt C, Vincus AA, Hanley S, Ennett ST, Bowling JM, Haws S. The prevalence of evidencebased drug use prevention curricula in U.S. middle schools in 2008. Prev Sci. 2009; 12(1):63-69. [PubMed: 20683664]

28. Ringwalt C, Vincus A, Hanley S, Ennett S, Bowling J, Rohrbach L. The prevalence of evidencebased drug use prevention curricula in U.S. middle schools in 2005. Prev Sci. 2009; 10(1):33-40. [PubMed: 19002583]

29. Quality Education Data Inc. QED National Education Database: Data Users Guide, Version 4.6. Denver, CO: Quality Education Data, Inc; 1998.

30. Ringwalt CL, Ennett S, Vincus A, Thorne J, Rohrbach LA, Simons-Rudolph A. The prevalence of effective substance use prevention curricula in U.S. middle schools. Prev Sci. 2002; 3(4):257-265. [PubMed: 12458764]

31. National Center for Education Statistics. [Accessed February 21, 2007] Public elementary/ secondary school universe survey data, 2002-03. Available at: http://nces.ed.gov/ccd/ pubschuniv.asp

32. National Registry of Evidence-Based Programs and Practices. [Accessed June 4, 2004] SAMHSA model programs. Available at: http://modelprograms.samhsa.gov

33. Center for the Study and Prevention of Violence. [Accessed June 4, 2004] Blueprints for violence prevention overview [University of Colorado, Boulder (CO) Web site]. Available at: http:// www.colorado.edu/cspv/blueprints/index.html

34. Safe, Disciplined, and Drug-Free Schools Expert Panel. [Accessed June 4, 2004] Exemplary Programs. Available at: http://www.ed.gov/admins/lead/safety/exemplary01/sddsguid.pdf and http://www.ed.gov/offices/OERI/ORAD/KAD/expert_panel/2001exemplary_sddfs.html

35. National Center for Education Statistics. [Accessed February 21, 2007] Public elementary/ secondary school universe survey data, 2003-04. Available at: http://nces.ed.gov/ccd/ pubschuniv.asp

36. Jones, SM.; Sutton, BC.; Boyle, KE. Survey methodology for studying substance use prevention programs in schools. In: Chaubey, YP., editor. Recent Advances in Statistical Methods. Proceedings of Statistics 2001 Canada. The 4th Conference in Applied Statistics. London: Imperial College Press; 2002. p. 157-168. 


\section{Table 1}

The Relationship Between Schools' 2005 AYP Status and Primary Use of EBC in $2008(n=1242)^{*}$

\begin{tabular}{lcc}
\hline Primary Use of EBC in 2005 & AYP Status in 2005 & Primary Use of EBC in 2008, \% (CI) \\
\hline Yes (hypothesis 1) & Adequate $(\mathrm{n}=211)$ & $59.3(52.1-66.5)$ \\
& Inadequate $(\mathrm{n}=100)$ & $57.1(44.9-69.4)$ \\
No (hypothesis 2) & Adequate $(\mathrm{n}=614)$ & $14.5(11.2-17.8)$ \\
& Inadequate $(\mathrm{n}=317)$ & $17.5(12.0-23.0)$ \\
\hline
\end{tabular}

AYP, adequate yearly progress; EBC, evidence-based curricula.

* Estimates are weighted and numbers are unweighted. 
Table 2

Characteristics of Schools by AYP Status as of $2005(\mathrm{n}=1304)^{\dagger}$

\begin{tabular}{|c|c|c|c|c|}
\hline & Made AYP $(n=867, \%)(95 \%$ CI $)$ & Did Not Make AYP $(n=437, \%)(95 \%$ CI $)$ & $\chi^{2}(\mathbf{d f})$ & p-Value \\
\hline \multicolumn{5}{|l|}{ Population density } \\
\hline Urban & $14.4(12.2-16.7)$ & $36.6(32.2-41.0)$ & $60.18(2)$ & $\mathrm{p}<.0001$ \\
\hline Suburban & $31.6(29.8-33.3)$ & $31.7(28.0-35.4)$ & & \\
\hline Rural & $54.0(51.8-56.2)$ & $31.7(26.7-36.8)$ & & \\
\hline \multicolumn{5}{|l|}{ Poverty ${ }^{*}$} \\
\hline Low $(0-14 \%)$ & $19.3(17.4-21.2)$ & $8.2(5.8-10.6)$ & $60.46(2)$ & $\mathrm{p}<.0001$ \\
\hline Medium(15-39\%) & $36.1(33.7-38.4)$ & $23.0(19.3-26.7)$ & & \\
\hline High $(>39 \%)$ & $44.6(42.2-47.0)$ & $68.8(64.7-72.9)$ & & \\
\hline \multicolumn{5}{|l|}{ School size } \\
\hline Small (<200 students) & $19.6(17.4-21.7)$ & $3.2(1.4-4.9)$ & $85.28(2)$ & $\mathrm{p}<.0001$ \\
\hline Medium(200-599 students) & $48.0(44.9-51.0)$ & $37.6(32.9-42.3)$ & & \\
\hline Large ( $\square 600$ students) & $32.5(29.8-35.1)$ & $59.2(54.5-63.9)$ & & \\
\hline \multicolumn{5}{|l|}{ Race/ethnicity } \\
\hline Majority White & $85.4(82.9-87.9)$ & $59.1(53.8-64.3)$ & $87.64(4)$ & $\mathrm{p}<.0001$ \\
\hline Majority African American & $4.7(3.2-6.3)$ & $17.6(13.2-22.1)$ & & \\
\hline Majority Hispanic & $4.0(2.6-5.4)$ & $11.2(8.2-14.1)$ & & \\
\hline Other majority & $1.5(0.5-2.5)$ & $1.9(0.3-3.5)$ & & \\
\hline No majority & $4.3(2.8-5.9)$ & $10.2(7.1-13.3)$ & & \\
\hline
\end{tabular}

AYP, adequate yearly progress.

* Proportion of students eligible for free or reduced-price lunch.

${ }^{\dagger}$ Estimates are weighted and numbers are unweighted. 
Table 3

Relationship Between AYP Status in 2005, School Sociodemographic Characteristics, and Primary Use of EBC in 2008, Among Schools Using and Not Using an EBC Most Frequently in $2005^{\S}$

\begin{tabular}{|c|c|c|c|c|}
\hline & \multicolumn{2}{|c|}{ Primary Use of EBC in $2005(n=312)$} & \multicolumn{2}{|c|}{ No Primary Use of EBC in $2005(n=944)$} \\
\hline & OR & AOR & OR & AOR \\
\hline Not making vs making AYP in 2005 & 0.92 & 0.88 & 1.25 & 1.26 \\
\hline \multicolumn{5}{|l|}{ Population density } \\
\hline Urban vs rural & 1.03 & 0.84 & 0.74 & 0.72 \\
\hline Suburban vs rural & $0.51^{*}$ & $0.39^{*}$ & 0.82 & 0.88 \\
\hline \multicolumn{5}{|l|}{ Poverty ${ }^{\dagger}$} \\
\hline Low vs high & 1.51 & 1.60 & 0.63 & 0.71 \\
\hline Medium vs high & 0.90 & 0.99 & 0.95 & 1.00 \\
\hline \multicolumn{5}{|l|}{ School size ${ }^{\ddagger}$} \\
\hline Small vs large & 0.69 & 0.46 & 0.87 & 0.94 \\
\hline Medium vs large & 1.30 & 1.00 & 1.05 & 1.00 \\
\hline \multicolumn{5}{|l|}{ Race/ethnicity } \\
\hline Majority African American vs majority White & 0.49 & 0.54 & 1.96 & 1.84 \\
\hline Majority Hispanic vs majority White & 2.14 & 2.33 & 0.93 & 0.92 \\
\hline Other majority vs majority White & 0.92 & 0.79 & 1.32 & 1.12 \\
\hline No majority vs majority White & 0.55 & 0.55 & 0.40 & 0.39 \\
\hline
\end{tabular}

OR, odds ratio; AOR, adjusted odds ratio; AYP, adequate yearly progress; EBC, evidence-based curricula.

* $\mathrm{p}<.05$.

${ }^{\dagger}$ Low: 0-14\% students eligible for free or reduced-price lunch; Medium: 15-39\%; High: >39\%.

FSmall: 20-199 students; Medium: 200-599; Large: 600+.

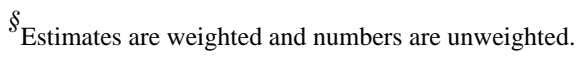

